\title{
El lugar imposible de las mujeres en seis novelas centroamericanas contemporáneas ${ }^{1}$
}

María Bonilla ${ }^{2}$

Universidad de Costa Rica, Costa Rica

\begin{abstract}
resumen
Se estudia la relación entre la búsqueda de la identidad, específicamente en las sociedades centroamericanas, con respecto a los lugares o espacios vitales que delimitan su existencia. De un corpus de sus novelas centroamericanas contemporáneas (2000-2010), se extraen relaciones significativas que hacen del espacio (real, buscado o imaginado) en punto de referencia existencial, moral o social. En cada novela se pone en entredicho el arraigado sistema de exclusión, de procedencia patriarcal.
\end{abstract}

\begin{abstract}
The relationship between the search for identity, specifically in Central American societies, is addressed with regard to those vital places or spaces which define their existence. Based on a corpus of contemporary Central American novels (2000-2010), significant relations are identified concerning their space (be it real, sought or imagined) from an existential, moral or social perspective. The existing system of exclusion with patriarchal roots is questioned in each of the novels.
\end{abstract}

Palabras clave: novela centroamericana contemporánea, narrativa femenina, mujer e identidad

Keywords: contemporary Central American novel, feminine narrative, women and identity

1 Ponencia presentada en el XX Congreso Internacional de Literatura Centroamericana (ciLca) 2012. Recibido: 30 de marzo de 2011; aceptado: 18 de abril de 2011.

2 Correo electrónico: mariabonilla@ costarricense.cr 
Hurgar en seis novelas centroamericanas en el lugar-no-lugar-lugar im-posible, que ocupan las mujeres, significa atravesar el mundo de la heterotopía, definida por Foucault (2004) como ciencia cuyo objeto serían esos espacios diferentes, esos otros lugares, impugnaciones míticas y reales del espacio en el que vivimos, donde la problemática del lugar que ocupa la mujer en la ficción literaria, nos refiere directamente a la complejidad misma del lugar que ocupa en la realidad histórica, premisa que aparece válida tanto para referirnos a Centroamérica, como a otras zonas del mundo.

Esos espacios diferentes, lugares que obedecen al binomio inclusión/exclusión, donde el otro lugar se constituye como otra realidad, pueden dar interesantes matices al referirlos a la notoria invisibilización que ha sufrido en la historia de la humanidad en general y en la del arte en particular, la participación femenina en la evolución de la especie, que en el campo de la creatividad, que desde mitad del siglo $\mathrm{xx}$, se ha visto fuertemente señalada y cuestionada. Invisibilización que opera como manifestación de la exclusión, tanto en la zona centroamericana como en otras partes del mundo.

Hemos elegido seis novelas que tienen protagonistas y narradoras femeninas y su temática refiere a la identidad como sujeto de creación y exploración: Más allá del Parismina (2004), de Carmen Naranjo (Costa Rica, 1928-2012); Candelaria del azar (2010), de Tatiana Lobo (Chile, 1939-Costa Rica); El rostro en el espejo (2005), de Carmen González Huguet (El Salvador, 1958); Sofía de los presagios (1997), de Gioconda Belli (Nicaragua, 1948); María la noche (2006), de Anacristina Rossi (Costa Rica, 1954); y Con pasión absoluta (2006), de Carol Zardetto (Guatemala), en la medida en que dan cuenta de propuestas sobre la realidad en sus posibilidades metafóricas, que muestran cómo ha vivido e interactuado la mujer con ese lugar que su mundo y su realidad le han asignado y que ha llevado a la necesidad histórica, estética, filosófica, pero fundamentalmente humana, de cuestionarlo, revisitarlo y redefinirlo como lugar posible.

Dentro del análisis de la problemática del lugar, cada una establece varios espacios de acción: un primer espacio es el contexto 
histórico, sexual, psicológico y social en el que se mueven las protagonistas, especie de lugar análogo, simbiótico, entre lo político y lo familiar, en que el país (espacio geo-socio-histórico-político, exterior) es metáfora de ellas mismas (espacio psicológico-emocionalsexual-espiritual, interior). Es decir, que hay una unión estructural que impide separar ambos espacios; lo político incide en lo familiar como si lo viéramos reflejado en un espejo cóncavo y a la inversa. El país, la cultura en que se vive, es el espacio significante de una vida que está vivida a imagen y semejanza de él.

Estas son novelas sobre lugares, sobre no-lugares y sobre lugares im-posibles. Según Marc Augé (2000), para la antropología el lugar es un espacio fuertemente simbolizado, en el cual leemos leer en parte o en su totalidad la identidad de los que lo ocupan, las relaciones que mantienen y la historia que comparten, donde cada uno conoce su sitio y el de los otros, un conjunto de puntos de referencias espaciales, sociales e históricas. Y un no-lugar, sería exactamente locontrario.

Así, las novelas elegidas dan cuenta de estos lugares de reconocimiento y elementos en común (el país en el que nacieron y el hogar paterno en el que vivieron las protagonistas, por ejemplo, o los lugares a los que emigraron o el hogar matrimonial y del marido o amante al que se fueron, por ejemplo) y de su pérdida. Las protagonistas descubren, a lo largo de la trama, con sorpresa y desconcierto, que son, al mismo tiempo, lugares de los que están excluidas, incluso más allá del género, aunque son lugares que forman parte estructural de quiénes son en tanto seres humanos:

Alguna vez afirmé que los guatemaltecos somos todos exiliados de la patria posible y estamos condenados a vivir una patria que se empeña en ser imposible. La frustración que esto provoca es angustiosa, pero a la vez muy fértil. En cuanto al amor, Guatemala es mi infancia, ¿cómo me saco ese amor $?^{3}$ 
Este espacio del lugar donde nacemos y crecemos, que a la vez es la infancia, nos define, desde esta cita, como exilados de la propia patria por un lado, pero sobre todo, de cualquier patria posible, porque la patria misma, es un imposible. Esta dimensión es también explícita en la novela El rostro en el espejo: «La casa es una metáfora del país. El Salvador es una casa con fantasmas. Básicamente la idea es que mientras uno no arregle cuentas con el pasado, vamos a tener que vivir la lección una y otra vez» ${ }^{4}$. Este lugar fantasmagórico, en el que se mezcla el pasado con el presente en el espacio de una casa, desdibujando ambos, exigiéndonos además, la rendición de cuentas, hace que la escritura femenina tenga una fuerte dimensión política, ética ehistórica:

La manera de encontrar sentido a la «obscenida» de nuestra sociedad es indagar en la historia y descubrir cómo ha moldeado las biografías que tanto nos importan. Cuando el individuo desarrolla una conciencia «histórica» deja de ser un sujeto pasivo de las circunstancias. Ese es un cambio fundamental. Yo creo que la literatura tiene un papel ineludible en la creación de significados. No existe comunicación inocente. (Zardetto)

Si revisamos la metáfora particularizada en el lugar familiar, adquiere dimensiones significantes acentuadoras. El marco de referencia familiar en el que se mueven las protagonistas, por un lado, testimonia de niñas-mujeres violadas por el padre y familiares cercanos y otras figuras masculinas en quienes se confía y no son extraños, como maestros y profesores o sacerdotes, por ejemplo, en Más allá del Parismina o en Sofía de los presagios. Esto hace del hogar paterno-materno, un lugar imposible y lo convierten en un extraño lugar de espejos, máscaras y juegos de poder:

Mamá reza, siempre lo hace al final, después del postre, cuando llega el café. Es su costumbre. Primero necesita confirmar que papá ha cumplido con su deber y solo entonces la comida recibe su bendición.

4 Carmen González Huguet, El rostro en el espejo (San Salvador: Editorial Roben H. Dimas, 2005). 
Papá inclina la cabeza. Por qué siempre inclina la cabeza. Papá inclina la cabeza pero no reza. Acata. ¿Acata o finge acatar? Yo también entro en la simulación. Mamá convierte a Dios en un paladar exigente, no bendice el alimento preparado por papá, le da el vistobueno.

En tal lugar encontramos fuerzas en conflicto, tratando de ejercer el poder: el padre y la madre y la religión y la educación. La mujer enfrenta otro enemigo, además del masculino, en aquellas madres cuya misión en la vida es hacer a sus hijas parte de un sistema que defienden en nombre del padre, muchas veces con la intención de protegerlas y asegurarles un futuro, aunque sea a través de someterlas a un sistema que las degrada, como vemos en la novela Con pasión absoluta, de Zardetto, donde la historia política de Guatemala en el siglo xx, está relacionada con una construcción de la sexualidad, en palabras de la propia autora, aberrante, como la sufre Irene, la protagonista:

Nunca pensé volver. Me fui para siempre el día que me fui. Vestida de blanco, como quería mi madre, quien me agradeció oficialmente años después esa condescendencia. Salir vestida de blanco, cumplir con tanta hipocresía. Quería cumplir... Me río de mí misma: la suerte me acompañó: sufrí un desengaño. El matrimonio podía ser un conjunto vacío, un espacio lleno de nada.

En María la noche, de Rossi, una madre sueña su familia como si fuera un lugar irreal, propio del mundo de las revistas estadounidenses, con hijos que tengan la apariencia de modelos. La protagonista, al ser distinta a este modelo ideal de la madre a pesar de ella, al cargar la evidencia de sus raíces caribeñas, sufre esta desviación de la visión de su madre, en carne propia. Esta mujer, Mariestela, ama, sin embargo, profundamente a su madre, así como la odia con la misma intensidad: 
A sus otros hijos los suponía idénticos a los de alguna revista americana: Good Housekeeping, Home and Gardens, blancos y de pelo lacio, normales, con las mismas aspiraciones y el mismo destino inevitable que los chiquitos gringos de las fotos, que vivían en el sumo de la normalidad: gringolandia. Nunca se tomó la molestia de situar mis desvaríos en tierra propia, en ese invernadero caribe, en ese fango más prolífico en bichos que cualquier otra tierra: su familia. (...) Sentí un dolor agudo que me cortaba la respiración, un dolor más extenso que el espacio entre las galaxias, un odio, una impotencia, el deseo de buscar a mi madre y hundirle un cuchillo en el mismito mismito corazón ${ }^{6}$.

La madre es la devoradora feroz del lugar que podría ocupar la hija en tanto ser humano individual, como muestra la novela Con pasión absoluta: «...aquello que siempre la había importado más que cualquier otra cosa a lo largo de su vida, las apariencias, se convirtió también en lo más importante para mí» ${ }^{7}$.

Este lugar de anulamiento de la hija, ocupado por la madre que la traga, pasa además y muy específicamente, por la sexualidad, como testimonia Irene: «Nacida en un país mojigato y castrador, me sentía francamente libre (...). La experiencia era excitante, por transgresora y porque sucedía en público, lo cual parecía convalidar mi protesta ${ }^{8}$.

Al mismo tiempo, este lugar del país y el hogar, de lo político y lo familiar, son el resultado del ejercicio abusivo e irracional del poder, de esa imposición de realidad, donde ante la agresión ni la certeza ayuda, y que aparece en la novela de González Huguet, El rostro en el espejo, como una fuente de cuestionamientos: «La lógica me dolía, definitivamente herida por el absurdo» ${ }^{9}$. El hecho de que el lugar de la patria y de la familia, tanto paterno-materna como la que se forma con el marido sea lugar de represión, desprecio, maltrato,

\footnotetext{
6 Anacristina Rossi, María la noche (Editorial Costa Rica, Costa Rica, 2006) 239.

7 Zardetto, 13.

8 Zardetto, 90.

9 González Huguet, 16.
} 
falta de libertad y anulación para la mujer, trae consecuencias. La primera: el silencio, como lo encontramos en Candelaria del azar con el personaje de Julieta:

Ya en la calle trozó un pedazo y se lo llevó a la boca, sabía a queso fresco, a mañanas de sol, al aire puro de las montañas, a la casa solitaria que tenía una cocina donde se acumulaba la leña con olor a ciprés, a una madre silenciosa, a unos hermanos durmiendo juntos en la misma cama y a su papá borracho que la mandó a bañarse en agua fría para que su mamá no se diera cuenta. Su madre sí se dio cuenta pero no dijo nada ese día, ni dijo nada cada vez que volvía a ocurrir lo mismo hasta que su padre fue perdiendo la vergüenza y la sacaba de la cama delante de todos para llevarla al galerón donde tenía un cuero de res tendido en el suelo. Julieta tampoco dijo nada entonces y no dice nada ahora... ${ }^{10}$

En este lugar, que debería ser refugio, protección, y es lugar de vejación, lugar ajeno, el silencio deviene mudez, pérdida de voz, de palabra, de articulación sobre el espanto.

La segunda consecuencia se articula cuando los imprevistos se viven - porque lo serán en realidad - como malos presagios, como le ocurre a Laura en Candelaria del azar: «Fue después cuando ella advirtió la presencia del muchacho y entonces ese día, que comenzó a las nueve de la mañana libre de premoniciones, se quebró hacia las cuatro de la tarde con la sospecha de un mal presagio ${ }^{11}$.

Esta incertidumbre ante lo imprevisto, puede devenir estrategia de protección, una forma no de insanidad, sino de táctica para sobrevivir, como en El rostro en el espejo: «Para entonces ya mi mente estaba más allá de la razón, y se había adaptado, cómodamente, a vivir en un mundo donde lo insólito era una parte integral de lo

10Lobo, 151.

11 Lobo, 13. 
cotidiano y donde en la vida real pasaban cosas más increíbles que en la imaginación $»^{12}$.

El mundo lo conforma lo insólito y la difuminación de las fronteras entre realidad y fantasía, un lugar de silencio, de incertidumbre. Una mujer es, en nuestras realidades centroamericanas $-\mathrm{y}$ posiblemente en otras también - por principio, menos que cualquier hombre, y una mujer sirvienta o esclava, pobre, negra o india, en un mundo de hombres blancos y de clases acomodadas, es menos que cualquier otra mujer, ocupando un lugar aún menos preciso, como podemos comprobar con el personaje de la India, en Candelaria del azar:

La India: Donde estaba sentada ahora no hay nadie. Se fue. No se sabe dónde, ni con quién, ni a qué. Quizá pertenecía al mercado negro de la mendicidad. Quizá formaba parte de un contingente de trabajadores itinerantes del café o de la caña. De ella vieron el vestido, de lo que había dentro de la tela nadie observó nada, si acaso tomaron nota de su pelo, por lo largo, lo negro y lo brillante. El pelo $\mathrm{y}$ un vestido amplio, grande, extendido como una flor pintada, nada más, y como era solo eso quién se iba a dar cuenta de su ausencia ${ }^{13}$.

La tercera consecuencia se constituye alrededor de la invisibilidad. Siendo una defensa contra este ejercicio de poder familiar y social, atraviesa la desaparición del propio cuerpo, de la identidad propia, de un lugar posible, aunque más no sea un pedacito de espacio donde sentarse y acomodar la ropa, como vimos en la India y como aparece en la novela Sofía de los presagios: «Todas las noches, cuando él la toca, trata de desaparecer en su cuerpo. Sólo no estando, imaginándose lejos, puede soportar aquella violación cotidiana» ${ }^{14}$. Un lugar lejano, imaginado, soñado, sin concreción física, deviene en lugar posible.

12 González Huguet, 18.

13 Lobo, 222.

14 Belli (1997), 39. 
La cuarta sería la mirada al lugar de la muerte. Cuando en Con pasión absoluta, Turin, el hermano de Irene, muere, la protagonista intenta encontrarle un sentido a esta muerte:

Mi hermano murió de lo mismo que se moría la gente allá en el Ixcán. La gente que él quería. Comió de su comida, durmió bajo su techo y murió como ellos: de una disentería. Sin medicinas, sin cuidados, como ellos. Gesto impráctico, pero subraya su integridad frente a la obscenidad cotidiana de una sociedad como la nuestra. Puedo equivocarme. Quizás fue simplemente una muerte más, de las inútiles y absurdas ${ }^{15}$.

Una muerte inútil, tampoco resulta un lugar posible. Al mismo tiempo, la muerte, ligada a la figura materna, ya vista en María la noche como un deseo de liberación del poder y control de la madre, aparece también para la hija, como un abandono a una realidad ante la cual está impotente y necesitada de esa defensa maternal, aunque ésta se revele, por diversas razones, inútil, como vemos en Sofía de los presagios: «No ha podido reconciliarse con su muerte tan imprevista. Siente que Eulalia, igual que su madre, la abandonó sin darle ninguna explicación. Se refuta a sí misma argumentando la ceguera de la muerte...» ${ }^{16}$.

La problemática del amor aparece también entre las consecuencias, en cuyo desencuentro, el papel del ejercicio de la violencia vuelve a jugar un papel indiscutible y clave, como vemos entre Julieta y su pareja en Candelaria del azar: «No estaba lista, el puño del Pintilla la sorprendió y la lanzó hacia atrás, no dolió, nada más la desazón en los dientes y una tristeza infinita en el pómulo, los ojos humedecidos por un imperceptible vaho parecido a la neblina del hogar paterno en esas tardes de dolor y miedo ${ }^{17}$. El amor que se mide

15 Zardetto, 360.

16 Belli, 46.

17 Lobo, 194. 
por la violencia, tampoco es un lugar posible para la mujer, por más que haya tenido la misma escuela en el hogar paterno.

En Más allá del Parismina, Isabel, mujer con ansias y deseos propios, quiere vivir en el presente, independiente del deseo masculino y no como un reflejo de éste, lo que hace que ella sienta angustia ante un tiempo que pasa y que ella no aprovecha, no vive:

Miguel, me da miedo el tiempo, me da mucho miedo, siempre hablás como si el tiempo fuera muy largo y la verdad es que se acaba, no quiero dejar las ilusiones para cuando seamos viejos, estoy llena de ahoras, porque es ahora cuando puedo disfrutar y no después, siento que crezco más que vos, que envejezco más rápido que vos, que necesito las cosas más rápido que vos ${ }^{18}$.

El concepto del tiempo, que las mujeres no tratan de definir ni de atrapar, sino de ubicar, para situarse ellas en él, y cuya ubicación se transforma en medida de la vida y del tiempo mismo, como en

Con pasión absoluta, es otra consecuencia: «Me veo con los ojos del recuerdo. Mis pasos recorren otra vez el camino de regreso: soy testigo de mí misma. Estoy presente en ese momento al que escojo llamar "entonces". Y porque estoy "presente" deja de ser pasado»"

También la problemática de la memoria es otro de los aspectos que se filtran como consecuencia, que se nos presenta como un obstáculo y una aliada al mismo tiempo, en el momento en que la requerimos en nuestra búsqueda de un lugar en el cual sea posible vivir, como en El rostro en el espejo: «... la casa logró tocar alguna fibra oculta en el fondo de mi propio corazón, y me llamó con una voz que no acertaba a reconocer; pero que de alguna manera presentía como propia. Algo en mí parecía entenderla, si no con el pensamiento, tal vez con una memoria más antigua que mis propios huesos $»^{20}$.

18 Naranjo, 20.

19 Zardetto, 14.

20 González Huguet, 11. 
El nombre aparece como otra consecuencia que se cuestiona desde el equívoco lugar que ocupa la mujer. El nombre, dado por la familia, por el padre, por el otro, resulta a veces también un lugar equívoco, como vemos en Candelaria del azar, donde a partir de un hecho común de delincuencia menor, (el robo de una cartera donde viene una cédula de identidad, documento que nos identifica a los costarricenses mayores de edad), se estructura una cadena de acontecimientos que se van interrelacionando entre sí y con los diversos personajes de la novela. La cédula de Candelaria se ve protagonista de una serie de delitos e investigaciones judiciales ajenos a su dueña. El nombre es acá, un elemento que no pertenece a ninguna persona o es elemento de suplantación de la persona, que permanece ajena a este uso. Es un nombre que perteneciendo a un ser humano, no lo representa; o representa a quien no quiere ser representado, a quien no tiene conciencia de ser representado, a quien no es.

A veces este nombre, cuando es dado por el amor, también parece hermoso, adquirible, aceptable, como en Más allá del Parismina:

Más allá, en otro pueblo, cuando las calenturas le dejaron formar su rostro justo, le dijo: te llamarás Isabel, así será más fácil todo. Ella no se negó, no era feo, eso de llamarse Isabel, si ella lo quería, el Josefa nunca le gustó y además el Isabel sonaba bonito y él lo repetía siempre, inclusive cuando ni siquiera sabía su nombre y apenas si se fijaba en sus largas miradas... ${ }^{21}$

El nombre aparece antes de la conciencia de lo que significa cargar un nombre, porque el amor aún es un lugar posible.

En este breve recorrido, se observa que al igual que en la realidad socio-histórico-política, en la que viven las mujeres, la ficción que estructuran las novelas seleccionadas dan cuenta de una situación de mudez, de un cuerpo vergonzante, de una invisibilización buscada ante la agresión o sufrida socialmente como prejuicio, de un olvido 
contradictorio, de un temor ante lo imprevisto, de un amor en el que es difícil confiar, de un tiempo emocional, mítico, de un nombre equívoco, de una muerte inútil, en fin, de un ejercicio del poder que hace invivibles los espacios y lugares en los que viven las mujeres.

Esto hace que las protagonistas emprendan interminables viajes de ida y vuelta de un lugar a otro, o de un no-lugar a otro, de un lugar im-posible a otro. Este viaje aparece como una huída imposible del hogar paterno en primer lugar, como en Con pasión absoluta: «He recorrido un círculo perfecto: salir de esta casa, de este país, para regresar a este país, a esta casa, feudo tenebroso de don Asunción $»^{22}$.

Además, aparece como una huída imposible también del hogar materno en el sentido figurado: de la protección y dominación de la madre. La huída supone una trampa: aparece como una ida hacia alguna parte distinta, pero en realidad, la mujer pronto descubre que es una ida hacia lo que se espera de ella (el matrimonio), que funciona como una sucursal de este hogar materno. Es ante el fracaso que luce como una pregunta sobre la posibilidad y la necesidad del regreso: «Me doy cuenta de que regresar es una imposibilidad. No se vuelve nunca a lo mismo, ni somos ya los mismos. (...) Entro y salgo de un pretérito anterior como quien lucha contra el sueño» ${ }^{23}$.

Ese sitio que no siempre es el que se esperaba, como ocurre con el matrimonio o con el cambio de país, implica un cambio de geografía o de espacio, mas no de circunstancias. En Con pasión absoluta, Irene abandona voluntariamente de Guatemala al norte del continente, buscando otros horizontes, otro lugar mejor y cuando regresa, la abruma el reencuentro con el lugar conocido: «Guatemala es un país jodido. Yo viví aquí siempre y por eso lo digo. Hay algo aquí duro, sórdido y siniestro: la columna vertebral que sostiene, organiza y hace funcionar a nuestra sociedad (...) Guatemala es asfixiante y cruda como la más exasperante de las pesadillas $»^{24}$.

22 Zardetto, 21.

23 Zardetto, 15.

24 Zardetto (2008). 
Este lugar al que se llega en el primer viaje de ida, aparece lleno de mitos que pesan sobre la mujer, mitos que al igual que los muebles de la sala, son lugares reconocidos por la mujer, incluso por el hombre que los ejerce, como en Más allá del Parismina:

... tal vez por eso te pegué y te encerré, guardé tu ropa bajo mil llaves y me empeñé en que fueras lo que no eras, la mujer de la revista, la del cuento azul, la que remienda la ropa nueva sin huecos, la que tiñe el color fijo de las ilusiones tontas. (...) te proclamé carcelera de mis infinitos egoísmos y te subí a un altar diabólico en que se te quemaba viva como a las brujas por no ser lo que no podías ser, hada encantada, señora del castillo, mujer de trovador, dama de salones, de esperas y conformidades ${ }^{25}$.

Son mitos ancestrales, funciones imposibles, demandas que no se pueden cumplir, lugares que no se pueden ocupar, los que definen el ser femenino desde la otredad individual masculina y colectiva social del poder. Entonces, la mujer que enfrentó la decisión de irse de ese lugar que no es propio, impulso que la motivó a un viaje que la colocó en un territorio ajeno nuevamente, se descubre en un lugar permanente de pasaje, de tránsito, tanto geográfico como temporal e interno, desde donde reconoce que debe volver para lo que González Huguet llamaba «el ajuste de cuentas» necesario para seguir adelante, pero que la hace re-encontrarse nuevamente con la imposibilidad.

Hablamos de procesos estrechamente vinculados con el exilio, aunque éste sea voluntario, como es el caso de Mariestela, que va a estudiar a Inglaterra, en María la noche:

Mi problema inmediato es que se me está olvidando el español. Casi todas las palabras se me han ido. Tengo cuatro para los sentimientos, como ocho para describir estados de ánimo, como diez para relacionarme con la gente y sólo tres para describirme $\mathrm{yo}^{26}$. 
La búsqueda imposible de un lugar posible, imagen del proceso de construcción-reconstrucción de la identidad femenina, es consecuencia de la precariedad de lo que significa tener un país, una ciudad, un barrio, como plantea García Canclini (Cf. Culturas híbridas,

1990), como una negación de todo aquello que la mujer no quiere seguir siendo, como un rechazo de esos elementos que debieran ser

la base misma del encuentro con un lugar posible. Lo afirma Carol Zardetto (2008): «Pero quizá más importante, mi novela arroja una mirada femenina sobre la Historia. Eso también fue fundamental para las mujeres, que parecían excluidas de la tragedia que hemos vivido».

La vida de la mujer es un lugar de extravío de la identidad en equívocos: el apellido del marido, las ollas, las funciones sociales, la apariencia, la imagen de ella desde los otros que la miran, su cuerpo que la avergüenza, la soledad y la dependencia del amor, una infancia de agresión, las violaciones que ha sufrido, como en Sofía de los presagios, o el exilio, aunque sea una estudiante en proceso de formación profesional, humana, femenina, como en María la noche. El hogar paterno, el hogar materno, el hogar matrimonial, no son lugares posibles para la mujer.

En María la noche, Mariestela, que sufría de identidad dividida entre su clase social de familia josefina con modelos estadounidenses y su vida en el Caribe limonense (zona atlántica, de cultura negra, muy pobre, de Costa Rica), aumenta esta fractura al marcharse a estudiar a Inglaterra. María la noche es una novela de construcción de identidad donde vemos a la protagonista, dividida como su país y su cultura, entre varios lugares, todos imposibles: el Caribe original, la Europa de sus estudios y profesión y el modelo de los Estados Unidos, variante de la propuesta que encontramos en El rostro en el espejo. En esta novela, ese lugar confuso, ambiguo y contradictorio de la identidad, es marca de las tensiones de la protagonista, transterrada entre varios lugares. El cambio de país, de cultura, de idioma incluso, es decir, el cambio de lugar geosocio-político, no es lugar posible para lamujer.

En El rostro en el espejo asistimos a la vida de una mujer que hereda una antigua casa en el campo salvadoreño, en la que vive, al 
mismo tiempo, un pasado que busca descanso, reconciliación, paz. La historia y viaje de Isabel, la protagonista, otorga a la autora la posibilidad de revisitar tradiciones indígenas y herencias europeas del linaje familiar, dualidad que conforma uno de los conflictos que vivía, y a lo mejor, vive aún. El Salvador del decenio de 1980, lugares todos de posible identificación, vivibles, aunque profundamente dolorosos y cuestionadores para ella. Es decir, estamos ante un lugar geopolítico que encierra el lugar temporal de lo ya vivido, así como el mestizaje propio de la zona, que deviene marca de identidad cultural. El pasado es pasado, es lugar de fantasmas, imposible para la mujer.

Con pasión absoluta es una novela que plantea un paralelismo entre la construcción sexual de la protagonista y la historia de su país, Guatemala, que se constituye en lugar invivible. En este caso, el lugar desterrado de la identidad nacional, que recubre el lugar de exilio de la sexualidad femenina, proscrita o reprimida por el lugar del poder, lugar del presente, son lugares imposibles.

En Candelaria del azar, hay varias protagonistas que resultan entrelazadas y casi una sola: la propia Candelaria, dueña e inquilina a la vez de su propio nombre, que afecta y ve afectada su vida por su nombre; Julieta, una Candelaria por robo de identidad y Laura, observadora de las Candelarias del mundo. Ellas tres están acompañadas por una Candelaria travesti, Sandra-José Rafael Vindas, hombre por fuera y mujer por dentro, eco bizarro de la Candelaria original y la India, sin nombre y sin lugar. Candelaria del azar es una metáfora aun más abstracta, aunque por ello, no menos real, sobre el lugar del nombre que habitamos o que nos habita, en tanto carga de identidad que no nos representa. El nombre resulta lugar no ubicable, no definible ni posible de asir, pero igualmente delimitado frente a nuestro ser. Tampoco el nombre es un lugar posible.

Estas metáforas de un lugar transmutado en cada una de las protagonistas-países, están entonces referidas tanto al lugar geográfico-socio-histórico, como a un lugar más abstracto, más interior, como ocurre en Sofía de los presagios, donde la metáfora nos 
interroga sobre el lugar imposible en el que podría sobrevivir un país, una cultura, una mujer, cuando en él, vive sometido a una violación cotidiana, ancestral, interminable, histórica e impune. El lugar de la herida deviene lugar invivible.

Más allá del Parismina es metáfora de la utopía del lugar buscado a lo largo de la vida, que no existe: un lugar donde ser libres, donde ser nosotras mismas, donde no tener que pedir permiso, donde no tener que disculparnos, un lugar que al estar más allá del Parismina (frontera sur de Costa Rica), está más allá de nuestras propias fronteras, de nuestros propios límites. Acá la utopía es cicatriz de la imposibilidad de ser.

Regresemos a Foucault (2004) que afirma:

Hay pues países sin lugar alguno e historias sin cronología. Ciudades, planetas, continentes, universos cuya traza es imposible de ubicar en un mapa o de identificar en cielo alguno, simplemente porque no pertenecen a ningún espacio. No cabe duda de que esas ciudades, esos continentes, esos planetas fueron concebidos en la cabeza de los hombres, o a decir verdad en el intersticio de sus palabras, en la espesura de sus relatos, o bien en el lugar sin lugar de sus sueños, en el vacío de su corazón; me refiero, en suma, a la dulzura de las utopías.

La literatura escrita por mujeres y las seis novelas visitadas en estas páginas, dan cuenta de ese lugar sin lugar de los sueños, de esa cartografía posible. Como afirma Gabriela Chavarría:

En este sentido, la literatura femenina y las seis novelas elegidas, dibujan como lugares en los que la mujer es: un lugar que está más allá, un rostro en el espejo, una noche de azar con pasión absoluta o un presagio, es decir, lugares imposibles, inexistentes, igual que en la realidad histórica, dando cuenta, al mismo tiempo, del trabajo constante de la mujer por ubicarse, repensarse e imaginarse en tanto ser humano, donde la escritura aparece, tal vez, como la heterotopía del único lugar posible en donde se puede vivir la dulzura o la amargura de aquello que carece de todo lugar. 